\title{
Desenvolvimento e desempenho reprodutivo de vacas primíparas aos 22/24 meses de idade
}

\author{
Alcides Pilau $^{1}$, José Fernando Piva Lobato $^{2}$ \\ ${ }^{1}$ Doutorando do Pós-Graduação em Zootecnia/Fac. de Agronomia - UFRGS. Bolsista CNPq. \\ ${ }^{2}$ Departamento de Zootecnia/Fac. de Agronomia - UFRGS, Caixa Postal 15100, CEP: 90.001-970, Porto Alegre, RS. Bolsista CNPq.
}

\begin{abstract}
RESUMO - Objetivou-se avaliar sistemas de alimentação para 70 novilhas de corte do início da gestação, aos 13/15 meses de idade, até o final do segundo período reprodutivo como vacas primíparas, aos 22/24 meses de idade. O delineamento experimental foi inteiramente casualizado com parcelas subdivididas no tempo considerando os animais como repetições. $\mathrm{O}$ peso vivo médio inicial foi de $282 \mathrm{~kg}$ e a condição corporal inicial de 3,2. Os sistemas de alimentação avaliados foram estabelecidos visando maior ganho de peso em pastagem cultivada na fase inicial (PCIG) ou final (PCFG) da gestação: PCIG - novilhas em pastagem de milheto (Pennisetum americanum, L.) durante a fase inicial da gestação e em pastagem natural no pré-parto; PCFG - novilhas em pastagem natural durante a fase inicial da gestação e em pastagem de aveia-preta (Avena strigosa Schreb) e azevém (Lolium multiflorum Lam) no pré-parto. Na fase inicial da gestação, o ganho de peso médio diário (GMD) de $0,424 \mathrm{~kg}$ das PCIG foi superior ao de $0,245 \mathrm{~kg}$ das PCFG. No pré-parto, as novilhas do sistema PCIG perderam peso, $0,303 \mathrm{~kg} /$ dia e condição corporal 0,77 ponto, enquanto as PCFG ganharam $0,901 \mathrm{~kg} /$ dia de PV e 0,37 ponto de CC. O peso vivo de $323 \mathrm{~kg}$ e a condição corporal de 3,3 pontos das novilhas do sistema PCFG pós-parto foram superiores aos das novilhas do sistema PCIG, de $274 \mathrm{~kg}$ e 2,6 pontos, respectivamente. As novilhas do sistema PCFG pariram bezerros $4 \mathrm{~kg}$ mais pesados e, ao início do período reprodutivo, apresentaram a mais $35 \mathrm{~kg}$ e 0,6 ponto de condição corporal. A taxa de prenhez de $85 \%$ das PCFG foi superior à de $53 \%$ das PCIG. As vacas prenhes foram as com maior condição corporal ao parto e ao início do segundo período reprodutivo, apresentaram maior intervalo do parto ao acasalamento e pariram bezerros mais pesados.
\end{abstract}

Palavras-chave: condição corporal, distocia, parto, peso vivo, sistemas a pasto

\section{Reproductive performance of primiparous cows at 22/24 months of age}

\begin{abstract}
The objective of this work was to evaluate the feed systems for 70 primiparous beef heifers from the initial gestation period at the age of $13 / 15$ months to the end of the second reproductive period as primiparous cows at $22 / 24$ months of age. The experimental design was fully random with plots subdivided in time considering animals as replicates The initial mean live weigh was $282 \mathrm{~kg}$ and the initial mean body condition was 3.2 . The feeding systems were proposed to obtain higher live weight gain at initial (PCIG) or final (PCFG) gestation period: PCIG - pregnant heifers on pearl millet pasture (Pennisetum americanum, L.) during the initial gestation period and on natural pasture at pre-calving period; PCFG pregnant heifers on natural pasture during the initial gestation period and on oat (Avena strigosa Schreb) and annual ryegrass (Lolium multiflorum Lam) pasture at pre-calving period. At initial gestation period, the mean live weight gain of $0.424 \mathrm{~kg}$ of PCIG heifers was higher than $0.245 \mathrm{~kg}$ of PCFG heifers. In the pre-calving period, PCIG heifers lost weight, $0.303 \mathrm{~kg} /$ day and presented $\mathrm{BC}$ of 0.77 , while PCFG heifers gained $0.901 \mathrm{~kg} /$ day and presented $\mathrm{BC}$ of 0.37 . The weight of $323 \mathrm{~kg}$ and body condition of 3.3 of post-calving PCFG heifers were higher than $274 \mathrm{~kg}$ and BC of 2.6 of PCIG heifers, respectively. PCFG heifers had calves $4 \mathrm{~kg}$ heavier. In the beginning of the second reproduction period, PCFG cows were $35 \mathrm{~kg}$ heavier and presented $\mathrm{BC}$ of 0.60 . The pregnancy rate of $85 \%$ of PCFG heifers was higher than $53 \%$ of PCIG heifers. Pregnant cows had the highest body condition rate at calving and at the beginning of the second reproduction period, presented higher calving and mating interval and heavier calves.
\end{abstract}

Key Words: body condition, dystocia, calving, live weight, grazing systems

\section{Introdução}

O número de bezerros desmamados em relação ao número de fêmeas do rebanho é fator determinante, direto ou indireto, da rentabilidade na atividade pecuária do Brasil. Altos índices reprodutivos possibilitam ocupar áreas destinadas a vacas não-gestantes e novilhas em crescimento com categorias produtivas, basicamente 
vacas e novilhas prenhes. Com isto, ocorrem aumento na geração de produto por hectare de pastejo e redução no custo energético por quilo de peso vivo produzido (Beretta et al., 2002), tornando-se necessária maior pressão de seleção para descarte de vacas e novilhas no início do período reprodutivo, aumentando o número de animais e de categorias a serem comercializados.

O desempenho reprodutivo de vacas primíparas afeta a resposta de todo o rebanho de cria. O estresse ao parto e os efeitos combinados entre crescimento e primeira lactação elevam os requisitos nutricionais, responsáveis pela baixa resposta reprodutiva quando essas vacas são submetidas a períodos de restrição alimentar pré e ou pós-parto (Spitzer et al., 1995).

O primeiro parto aos $22 / 24$ meses de idade torna a vaca primípara ainda mais vulnerável em comparação àquelas preparadas para iniciar a fase reprodutiva em idades mais avançadas, em virtude da necessidade de maiores taxas de ganho de peso em contraste com o menor tamanho corporal, o que pode resultar em elevadas taxas de distocia. A perda neonatal de bezerros por distocia é o fator de maior impacto negativo na eficiência de produção de bovinos de corte nos Estados Unidos (Bellows \& Short, 1994), onde 95\% das fêmeas são expostas à reprodução aos 13/15 meses de idade (Merck Sharp Dome-MSD, 1992). A manipulação do ganho de peso e da condição corporal durante a gestação, portanto, é um desafio na pecuária brasileira. É necessário buscar peso adequado ao parto sem promover excessivo desenvolvimento do bezerro no período neonatal.

O terço final da gestação em fêmeas bovinas é o período de maior restrição alimentar (Lobato et al., 1998; Vieira et al., 2005). Para a novilha prenhe aos $13 / 15$ meses de idade manter-se em gestação, parir em condições de criar bem o bezerro e conceber no período reprodutivo subseqüente, deve ter bom ganho de peso durante a gestação. Para obtenção de índices satisfatórios de prenhez em primíparas aos 34/36 meses de idade, segundo Rovira (1996), a novilha prenhe com $65 \%$ do peso adulto deve parir com $80 \%$ e atingir $85 \%$ ao início do segundo período reprodutivo.

Novilhas prenhes aos 13/15 meses de idade, sistema "um ano" de produção, têm um ano a menos de recria, o que dificulta atingir estas metas de peso. Definir o momento da gestação é adequado para maior ganho de peso e a relação desse ganho de peso com a condição corporal da fêmea pode auxiliar na obtenção de respostas satisfatórias a pasto para o sistema "um ano" no Brasil.

A hipótese em estudo é que o melhor nível alimentar no terço final de gestação possibilita à novilha gestante a partir dos 13/15 meses de idade parir em melhores condi- ções para criar seu bezerro e conceber no segundo período reprodutivo em comparação a maior nível alimentar na fase inicial da gestação e com restrição pré-parto. Assim, avaliaram-se o desenvolvimento e o desempenho reprodutivo de novilhas primíparas aos 22/24 meses de idade submetidas a maior nível alimentar no período inicial ou final da gestação.

\section{Material e Métodos}

O experimento foi realizado em área da Agropecuária Nossa Senhora de Lourdes, município de Tupanciretã, Rio Grande do Sul, no período de novembro de 2004 a março de 2006. A propriedade está localizada na região fisiográfica denominada Planalto Médio, com altitude média de $180 \mathrm{~m}$, latitude $29^{\circ} 03^{\prime}$ 'Sul e longitude $53^{\circ} 48^{\prime}$ Oeste.

O relevo da região é ondulado, de solos profundos, naturalmente ácidos e de textura superficial média. O solo é classificado como Latossolo Vermelho Distroférrico típico (EMBRAPA, 1999) e o clima da região é subtropical, conforme classificação de Köppen (Moreno, 1961).

Foram utilizadas 78 novilhas (53 da raça Aberdeen Angus e 25 mestiças Angus) expostas à reprodução aos 13/15 meses de idade, provenientes da Cabanha Capitão Rodrigo (Jari, Rio Grande do Sul).

No primeiro período reprodutivo (16/11/2004 a $30 / 1 / 2005$ ), as 78 novilhas foram mantidas em pastagem natural. As espécies mais freqüentes nas pastagens naturais desta região são grama-forquilha (Paspalum notatum), grama-tapete (Axonopus affinis), capim-caninha (Andropogon lateralis), pega-pega (Desmodium encanum) e cabelo-deporco (Piptochaetium stipoides).

A partir de 18/12/2004, para início dos regimes de alimentação, as novilhas foram distribuídas considerando os dois grupos raciais (Angus e mestiças Angus) e os dois regimes de alimentação em cada faixa de peso vivo. As novilhas diagnosticadas como gestantes, 70 no total, pela técnica de ultra-sonografia com transdutor transretal linear detra $5 \mathrm{MHz}$ de freqüência, realizada em $8 / 3 / 2005$, foram consideradas testes e as demais, 8 novilhas, foram utilizadas como animais reguladores no ajuste da carga animal. As novilhas-testes, prenhes, com peso médio de $282 \mathrm{~kg}$ e condição corporal inicial de 3,2 (escala de 1 a 5), foram distribuídas em dois sistemas de alimentação, visando ganho de peso em pastagem cultivada ao início (PCIG) ou ao final da gestação (PCFG):

PCIG - novilhas prenhes manejadas em pastagem de milheto (Pennisetum americanum, L.) durante a fase inicial da gestação e em pastagem natural no pré-parto;

PCFG - novilhas prenhes em pastagem natural durante a fase inicial da gestação e pastagem de aveia- 
preta (Avena strigosa Schreb) e azevém (Lolium multiflorum Lam) pré-parto.

Durante a gestação, nos sistemas alimentares PCIG e PCFG, foram mantidos 37 e 33 animais-teste, respectivamente. O período de pastejo das novilhas em pastagem de milheto foi de 18/12/2004 a 21/4/2005, totalizando 124 dias e o das novilhas em pastagem de aveia-preta e azevém, de 2/7/2005 a 26/10/2005, totalizando 116 dias.

Os animais foram manejados em grupo único, em pastagem natural, no intervalo entre a pastagem de milheto e a de aveia e azevém. No pós-parto, em aveia e azevém e, durante o segundo período reprodutivo, em pastagem natural. A área de pastagem de milheto foi de $10 \mathrm{ha}$, a de pastagem natural de 85 ha e a de aveia e azevém, de 37 ha.

O segundo período reprodutivo ocorreu de 27/10/2005 a 12/2/2006. Foram utilizados três touros Red Angus de 3 anos de idade submetidos previamente a exame andrológico.

O método de pastejo foi o contínuo com lotação variável, empregando-se a técnica do uso de animais reguladores (Mott \& Lucas, 1952) para o ajuste da carga animal às massas de forragem (MF) pretendidas. Na pastagem de aveia e azevém, procurou se manter a massa de forragem entre 1.200 e $1.800 \mathrm{~kg} / \mathrm{ha}$ MS. Na pastagem natural e na de milheto, a massa de forragem pretendida foi de 1.500 a $2.000 \mathrm{~kg} / \mathrm{ha} \mathrm{MS}$.

$\mathrm{O}$ ajuste de carga animal e as medidas de massa de forragem, taxa de acúmulo de forragem (TAD) e oferta de forragem (OF) foram realizados em intervalos de aproximadamente 28 dias. A massa de forragem foi determinada pela técnica de dupla amostragem (Wilm et al., 1944). Para determinação da taxa de acúmulo diário, foram alocadas cinco gaiolas de exclusão ao pastejo por área de pasto, utilizando-se metodologia descrita por Klingmann et al. (1943). A oferta de forragem (OF) foi calculada dividindo-se a massa de forragem por 28 dias somada à taxa de acúmulo diário. O valor obtido foi multiplicado por 100 e dividido pela carga animal.

A determinação do valor nutritivo da forragem foi realizada utilizando-se amostras colhidas por simulação de pastejo (Gibb \& Treacher, 1976), analisadas quanto aos teores de proteína bruta $(\mathrm{PB})$ e fibra em detergente neutro (FDN), conforme técnicas descritas pela Association of Official Analytical Chemists (AOAC, 1984).

As pesagens foram realizadas após jejum de 6 horas. $\mathrm{Na}$ fase inicial de gestação, os animais foram pesados no início do pastejo em milheto (18/12/2004), em 30/1/2005, $22 / 2 / 2005 ; 3 / 4 / 2005$ e ao final do pastejo do milheto (21/4/2005). Na pastagem de aveia e azevém, as pesagens foram realizadas em 2/7/2005 (início do pastejo), em 26/8/2005 e 26/10/2005 (final do período de pastejo). As vacas também foram pesadas ao parto, no máximo 12 horas após o nascimento dos bezerros, que também foram pesados e identificados com brinco plástico.

Em cada pesagem, foi avaliado o escore de condição corporal (Lowman et al., 1973), realizado por dois avaliadores treinados. O escore final foi composto pela média dos dois avaliadores, com valores de 1 a $5(1=$ muito magro e $5=$ muito gordo), exceto na pesagem ao parto. O escore de condição corporal ao parto foi calculado considerando o ganho de condição corporal do início da pastagem de aveiapreta e azevém até a última avaliação pré-parto. O escore obtido foi ajustado para o número de dias até o parto e depois, somado à condição corporal ao início da pastagem hibernal, conforme metodologia adaptada de Hight (1966).

No segundo período reprodutivo, as pesagens foram realizadas ao início (26/10/2005), em 26/12/2005 e no final em 13/2/2006. No total, foram 109 dias de período de acasalamento.

O controle de endoparasitos foi realizado por meio de dosificações com vermífugos de amplo espectro aos animais no início do período de pastejo e, posteriormente, a cada quatro pesagens. O ganho de peso médio diário (GMD) foi obtido pela diferença entre peso final e inicial dos animais-teste em cada período experimental, dividido pelo número de dias do período.

As variações diárias de peso na fase pré-parto foram calculadas como a diferença entre o peso na última pesagem antes do parto e aquela realizada ao início da pastagem de aveia e azevém. O valor obtido foi dividido pelo número de dias entre as pesagens, conforme descrito por Hight (1966). Na fase pós-parto, as variações diárias de peso das vacas foram calculadas como a diferença entre o peso em $26 / 10 / 2005$, final da pastagem de azevém e início do segundo período reprodutivo, e o peso ao parto. O valor obtido foi dividido pelo número de dias entre as pesagens e as variações de condição corporal, por meio de adaptação dos critérios adotados para a variação diária de peso. No pré-parto, foi calculada a diferença entre a última condição corporal observada antes do parto e a condição corporal ao início da pastagem de aveia e azevém. Na fase pós-parto, foi calculada a diferença entre a condição corporal ao início do segundo período reprodutivo e a condição corporal ao parto.

A taxa de parição correspondeu ao percentual de vacas paridas; a taxa de natalidade, à porcentagem de bezerros vivos até 24 horas após o parto; e a taxa de desmame, à porcentagem de bezerros ao final do período reprodutivo, todas em relação ao total de vacas prenhes ao início do experimento. A taxa de distocia foi determinada como a porcentagem de vacas com dificuldade de parto em relação ao número de vacas paridas. 
Depois do parto, foram consideradas repetições somente vacas-teste com cria ao pé. As vacas cujos bezerros foram perdidos foram mantidas como animais reguladores no ajuste da carga animal. A taxa de prenhez representou a porcentagem de vacas com cria ao pé prenhes no segundo período reprodutivo.

O diagnóstico de gestação do segundo período reprodutivo foi realizado 82 dias após o seu término (6/5/2006), pela técnica de ultra-sonografia com transdutor transretal linear de $5 \mathrm{MHz}$ de freqüência. As vacas foram classificadas de acordo com o desenvolvimento do embrião, em vacas prenhes no terço inicial, intermediário ou final da estação de monta, respectivamente.

As estimativas das medidas de eficiência produtiva foram obtidas por meio das características quantificadas, conforme metodologia descrita por Ribeiro et al. (2001). A primeira estimativa de eficiência foi considerada a quantidade de kg de bezerros ao final do período reprodutivo para cada $100 \mathrm{~kg}$ de vacas paridas: $\mathrm{EPVP}=(\mathrm{P} 100 / \mathrm{PVP}) * 100$, em que $\mathrm{EPVP}=$ eficiência produtiva ao parto; $\mathrm{P} 100=$ peso do bezerro ajustado aos 100 dias de idade; e PVP = peso da vaca ao parto. A segunda estimativa foi eficiência produtiva ao final do período reprodutivo (EPVF), na qual o PVP foi substituído pelo peso da vaca ao final do período reprodutivo $(\mathrm{PVF}): \mathrm{EPVF}=(\mathrm{P} 100 / \mathrm{PVF}) * 100$.

O delineamento experimental foi inteiramente casualizado com parcelas subdivididas no tempo considerando os animais como repetições. Os dados coletados foram submetidos à análise de variância e ao teste $\mathrm{F}$ utilizando-se o seguinte modelo matemático na análise:

$$
\mathrm{Y}_{\mathrm{ijkl}}=\mu+\mathrm{T}_{\mathrm{i}}+\mathrm{A}_{\mathrm{j}}(\mathrm{T})_{\mathrm{i}}+\mathrm{P}_{\mathrm{k}}+(\mathrm{T} * \mathrm{P})_{\mathrm{ik}}+\varepsilon_{\mathrm{ijk}},
$$

em que: $\mathrm{Y}_{\mathrm{ijk}}=$ variáveis dependentes; $\mu=$ média de todas as observações; $\mathrm{T}_{\mathrm{i}}=$ efeito do i-ésimo tratamento alimentar; $A_{j}(T)_{i}=$ efeito do j-ésimo animal dentro do i-ésimo tratamento alimentar (erro A); $\mathrm{P}_{\mathrm{k}}=$ efeito do k-ésimo período; $\left(\mathrm{T}^{*} \mathrm{P}\right)_{\mathrm{ik}}=$ efeito de interação entre o i-ésimo tratamento alimentar e o k-ésimo período; $\varepsilon_{\mathrm{ijk}}=$ erro residual (erro B).

Quando detectada diferença entre sistemas de alimentação, foi realizado o teste Tukey para comparação de médias. As análises foram feitas pelo procedimento "general linear model"(GLM). Os dados referentes à taxa de prenhez e velocidade de concepção foram analisados pelo método do qui-quadrado utilizando-se o programa estatístico SAS, versão 6.08 (SAS, 1997), com nível máximo de 5\% de significância.

\section{Resultados e Discussão}

$\mathrm{Na}$ fase inicial de gestação, a oferta de forragem média na pastagem de milheto, de $9 \mathrm{~kg} \mathrm{MS} / 100 \mathrm{~kg} P V$, correspondeu à oferta preconizada para o manejo desta forrageira sob pastejo (Tabela 1) e não foi limitante para o desempenho animal, uma vez que a necessidade desta forrageira é três vezes superior ao consumo estimado para animal sob pastejo (Gibb \& Treacher, 1976), portanto, correspondente a 2,8\% para esta categoria animal (NRC, 1996).

A área de pastagem natural ocupou áreas marginais aos solos de coxilhas, formadas por áreas parcialmente drenadas e encostas. Neste período, o ajuste de carga animal, de $237 \mathrm{~kg} / \mathrm{ha} P V$, resultou em elevada oferta de forragem, $28 \mathrm{~kg} \mathrm{MS} / 100 \mathrm{~kg}$ PV. A taxa de acúmulo de forragem, de $22 \mathrm{~kg} / \mathrm{ha} \mathrm{MS}$, foi superior ao potencial de consumo das novilhas, gerando aumento da massa de forragem até o final do período. A massa de forragem média de $1.224 \mathrm{~kg} / \mathrm{ha} \mathrm{MS}$ não permitiu a estrutura da pastagem se tornar grosseira, pois o período de pastejo foi restrito a 124 dias de pastejo. O manejo da pastagem natural durante a estação de crescimento permitiu manter as novilhas com oferta de forragem de $16 \mathrm{~kg} \mathrm{MS} / 100 \mathrm{~kg}$ PV no outono e inverno pré-parto.

Na pastagem de aveia e azevém utilizada no pré-parto, a massa de forragem média foi de $790 \mathrm{~kg} / \mathrm{ha}$ MS. Quando a massa de forragem é mantida em níveis inferiores a $1.200 \mathrm{~kg} / \mathrm{ha}$ MS, o consumo é reduzido (Mott, 1984) e o desempenho dos animais fica abaixo do potencial (Rocha et al., 2003). A massa de forragem foi mantida próxima a $1.000 \mathrm{~kg} / \mathrm{ha}$ MS, visando restringir, em parte, o desempenho das novilhas em fim de gestação e evitar o crescimento excessivo do feto no período neonatal. Embora com $12 \mathrm{~kg}$ MS/100 kg PV de oferta de forragem, a baixa altura da pastagem dificultou maior profundidade do bocado e,

Tabela 1 - Características das pastagens natural, de milheto e de aveia e azevém utilizadas na fase inicial de gestação e no pré-parto

\begin{tabular}{|c|c|c|c|c|c|c|}
\hline \multirow{2}{*}{$\begin{array}{l}\text { Variável } \\
\text { Pastagem }\end{array}$} & \multicolumn{2}{|c|}{ Início da gestação } & \multicolumn{2}{|c|}{ Pré-parto } & Pós-parto & Acasalamento \\
\hline & Milheto & Natural & Aveia e azevém. & Natural & Aveia e azevém & Natural \\
\hline Massa de forragem (kg/ha MS) & 1.531 & 1.224 & 790 & 1.037 & 1.330 & 1.325 \\
\hline Taxa de acúmulo diário (kg/ha MS) & 78 & 22 & 25 & 3 & 65 & 18 \\
\hline Oferta de forragem (kgMS/100 kgPV) & 9 & 28 & 12 & 16 & 21 & 31 \\
\hline Carga animal (kg/ha PV) & 1442 & 237 & 435 & 462 & 540 & 208 \\
\hline Proteína bruta $(\%)$ & 18,4 & 11,6 & 16,1 & 13,6 & 12,8 & 11,2 \\
\hline Fibra em detergente neutro $(\%)$ & 65 & 71 & 61 & 73 & 67 & 70 \\
\hline
\end{tabular}


Tabela 2 - Desenvolvimento das novilhas da fase inicial de gestação até o parto

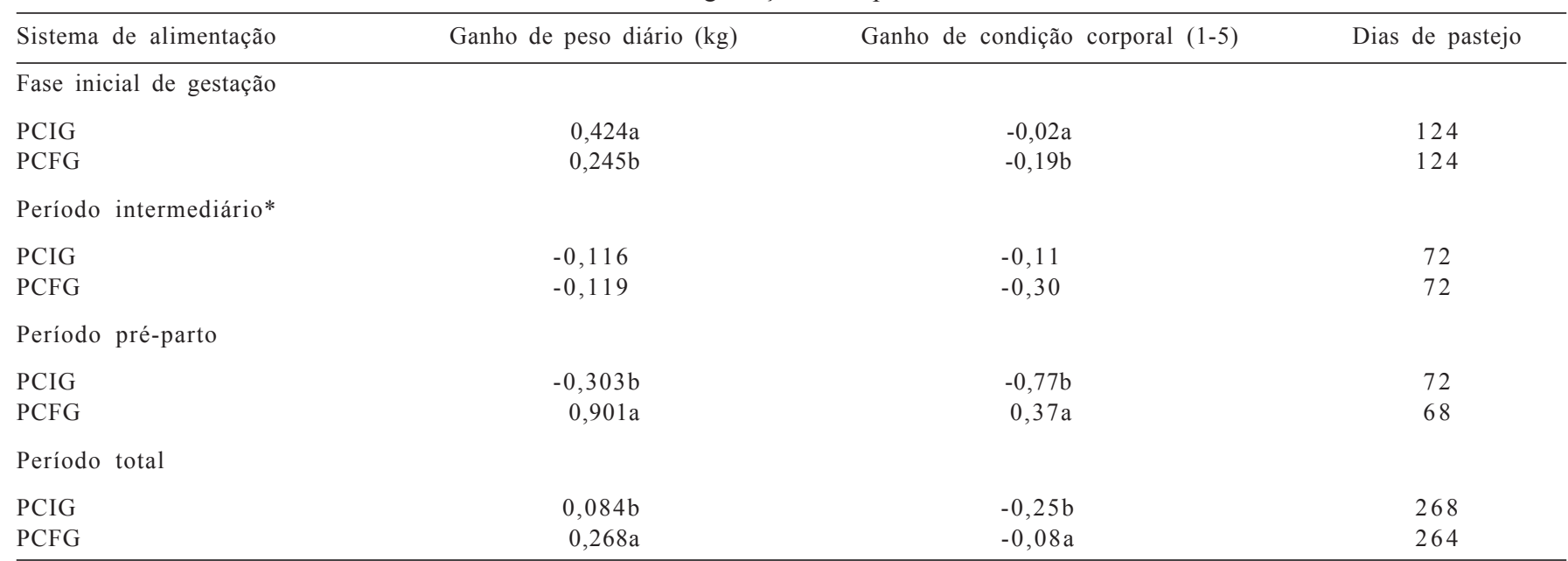

a, b na mesma coluna diferem entre si $(\mathrm{P}<0,01)$.

* Todas as novilhas em pastagem natural.

PCIG - pastagem de milheto na fase inicial de gestação e pastagem natural no pré-parto.

PCFG - pastagem natural na fase inicial de gestação e pastagem de aveia e azevém no pré-parto.

conseqüentemente, o volume de ingestão pelo animal (Carvalho et al., 2001). No pós-parto, a maior oferta de forragem, $21 \mathrm{~kg} \mathrm{MS} / 100 \mathrm{~kg} \mathrm{PV}$, associada à taxa de acúmulo de forragem de $65 \mathrm{~kg} / \mathrm{ha} \mathrm{MS}$, resultou em massa de forragem média de $1.325 \mathrm{~kg} / \mathrm{ha} \mathrm{MS}$, aumentando a eficiência de colheita de forragem das vacas com cria ao pé.

Durante os 124 dias iniciais do período de gestação (Tabela 2), o ganho médio diário de $0,424 \mathrm{~kg}$ das novilhas em pastagem de milheto (PCIG) foi superior ao de $0,245 \mathrm{~kg}$ daquelas em pastagem natural (PFIG) no início da gestação (Tabela 2). Nesse período, tanto as novilhas em PCIG como aquelas em PCFG perderam condição corporal. Entretanto, a perda nas novilhas em PCFG, de 0,19 ponto, foi superior à de 0,02 ponto das novilhas em PCIG, que praticamente mantiveram a condição corporal inicial de 3,2.

Os ganhos de peso obtidos foram inferiores ao potencial produtivo das pastagens. Resultados de outras pesquisas indicam ganhos de peso de novilhas em milheto de 0,80 a 1,0 kg/dia (Rocha et al., 2004; Pilau \& Lobato, 2006). Em pastagem natural, têm sido medidos ganhos de peso de novilhas na estação de crescimento, primavera-verão, de 0,30 a 0,40 kg/dia (Pereira Netto et al., 1999; Pio de Almeida \& Lobato, 2004). O bom desenvolvimento inicial das novilhas neste trabalho contribuiu para menor ganho de peso, em decorrência do aumento das suas exigências para mantença. As diferenças de deposição de gordura nos diversos tecidos do corpo podem alterar a proporção de tecidos metabolicamente ativos, modificando as relações entre mantença e peso vivo (Buckley et al., 1990).

$\mathrm{Na}$ pastagem natural no outono, após o término do milheto, tanto as novilhas em PCIG como as em PCFG perderam peso $(0,118 \mathrm{~kg} / \mathrm{dia})$ e condição corporal nos 72 dias de pastejo (0,20 ponto). No pré-parto, em aveia e azevém, as novilhas em PCFG apresentaram ganho médio diário de $0,901 \mathrm{~kg}$ e ganho de condição corporal de 0,37 ponto durante 72 dias. As novilhas em PCIG perderam peso e condição corporal, $0,303 \mathrm{~kg} / \mathrm{dia}$ e 0,77 ponto, respectivamente, em um período médio de 68 dias em pastagem natural. Houve considerável ganho de peso das novilhas em PCFG e redução do desempenho das novilhas em PCIG.

Restrição alimentar pré e pós-parto resulta em baixo peso ao parto, prolongado intervalo de anestro pós-parto e baixo índice de vacas ciclando no período reprodutivo subseqüente (Spitzer et al., 1995; Gottschall \& Lobato, 1996). Elevado ganho de peso da vaca pré-parto é o principal determinante de maior peso ao nascer do bezerro, que está diretamente relacionado à incidência de distocia. Segundo Bellows et al. (1996), as medidas de tamanho corporal da novilha na estação reprodutiva não têm relação com o peso ao nascer do bezerro. Portanto, para facilidade ao parto, não basta selecionar as novilhas antes do período reprodutivo, aos 13/15 meses de idade, pois elevadas taxas de ganho de peso pré-parto aumentam a incidência de distocia.

Ao parto, as vacas em PCFG foram, na média, $47 \mathrm{~kg}$ mais pesadas, tiveram 0,7 ponto a mais de condição corporal e pariram bezerros $4 \mathrm{~kg}$ mais pesados em relação às em PCFG (Tabela 3 ). Ciccioli et al. (2003) não verificaram diferença no peso ao nascer do bezerro de primíparas com condição corporal ao parto de 4 e 5 pontos na escala de 1 a 9 , escores de condição corporal similares às deste trabalho na escala de 1 a 5 pontos. No entanto, os autores não verificaram diferença no peso no parto. O elevado 
Tabela 3 - Desempenho pós-parto de vacas primíparas, aos $22 / 24$ meses de idade, mantidas em dois sistemas de alimentação durante a gestação

\begin{tabular}{lccc}
\hline & \multicolumn{2}{c}{$\begin{array}{c}\text { Sistema de } \\
\text { alimentação }\end{array}$} & \multirow{2}{*}{ Média } \\
\cline { 2 - 3 } & PCIG & PCFG & \\
\hline Peso vivo, kg & $274 \mathrm{~b}$ & $323 \mathrm{a}$ & \\
Condição corporal (1-5) & $2,6 \mathrm{~b}$ & $3,3 \mathrm{a}$ & \\
Variação diária de peso, kg & 0,428 & 0,549 & 0,488 \\
Variação da condição corporal (1-5) & 0,33 & 0,19 & 0,26 \\
Peso ao nascer dos bezerros, kg & $27 \mathrm{~b}$ & $31 \mathrm{a}$ & \\
\hline
\end{tabular}

a, b na mesma linha, diferem $(\mathrm{P}<0,01)$ entre si.

PCIG - pastagem de milheto na fase inicial de gestação e pastagem natural no préparto; PCFG - pastagem natural na fase inicial de gestação e pastagem de aveia e azevém no pré-parto.

ganho de peso pré-parto das novilhas em pastagem de aveia-preta e azevém (Tabela 2) foi determinante para o aumento do peso ao nascer dos bezerros. Spitzer et al. (1995) não verificaram influência do escore de condição corporal na taxa de distocia.

No período pós-parto não houve diferença no desempenho entre as vacas mantidas nos sistemas de alimentação. A variação diária de peso (VDP) foi de $0,488 \mathrm{~kg}$ e a variação na condição corporal (VCC), de 0,26 ponto até o início do período reprodutivo. As primíparas aos 22/24 meses mantidos com dietas de média qualidade no pósparto perderam 0,26 ponto de condição corporal durante 45 dias, ao passo que aquelas mantidas com dieta de alta qualidade tiveram ganho de condição corporal de 0,45 ponto na escala de 1 a 9 pontos (Ciccioli et al., 2003). Com maior nível nutricional no pós-parto, Ribeiro et al. (2001) perceberam maior produção de leite, bezerros mais pesados ao desmame e maior produtividade dos rebanhos de cria.

Não houve diferença entre seqüências de alimentação das primíparas para as taxas de parição, distocia, natalidade e desmame (Tabela 4). A taxa de parição média foi de $93 \%$ e a de desmame, de $83 \%$, em relação ao número total de novilhas prenhes aos 13/15 meses de idade. Segundo Grimard et al. (1995), mortalidade embrionária, aborto, perda perinatal de bezerros e debilidade da vaca no pósparto ocorrem em maiores proporções em primíparas em relação a multíparas.

A taxa de distocia média de $13 \%$ pode ser considerada baixa para primíparas aos 22/24 meses de idade. Entretanto, houve indicativo de aumento na taxa de distocia nas novilhas em pastagem de aveia-preta e azevém pré-parto $(\mathrm{P}=0,07)$. As vacas em PCFG com problemas de distocia tiveram $0,120 \mathrm{~kg}$ de ganho de peso diário, 0,22 ponto no ganho de condição corporal e 16 dias de pastejo a mais pré-parto em aveia e azevém em relação à média das com parto normal, além de parir bezerros $4 \mathrm{~kg}$ mais pesados.
Tabela 4 - Taxas de parição, distocia, natalidade e desmame de vacas primíparas aos $22 / 24$ meses de idade mantidas em dois sistemas de alimentação durante a gestação

\begin{tabular}{lcccc}
\hline $\begin{array}{l}\text { Sistema de } \\
\text { alimentação }\end{array}$ & $\begin{array}{c}\text { Parição } \\
(\%)\end{array}$ & $\begin{array}{c}\text { Distocia } \\
(\%)\end{array}$ & $\begin{array}{c}\text { Natalidade } \\
(\%)\end{array}$ & $\begin{array}{c}\text { Desmame } \\
(\%)\end{array}$ \\
\hline PCIG & 89 & 6 & 81 & 81 \\
PCFG & 97 & 19 & 85 & 85 \\
Média & 93 & 13 & 83 & 83 \\
\hline
\end{tabular}

$\mathrm{P}>0,05$.

PCIG - pastagem de milheto na fase inicial de gestação e pastagem natural no préparto

PCFG - pastagem natural na fase inicial de gestação e pastagem de aveia e azevém no pré-parto.

Em trabalho com fêmeas da raça Angus, Berger et al. (1992) observaram maiores problemas de distocia nas vacas de bezerros com peso ao nascer superior a $31 \mathrm{~kg}$, pesos semelhantes às médias de peso ao nascer dos bezerros das novilhas em pastagem de aveia-preta e azevém pré-parto (Tabela 3). Os principais fatores causadores de distocia são peso do bezerro ao nascer e limitação de área pélvica e, em segundo plano, baixo peso pré-parto e sexo do bezerro (Bellows et al., 1996).

O consumo de alimentos pelas primíparas durante a gestação e no pós-parto pode ser manipulado para a obtenção de escores de condição corporal e ganhos de peso específicos para alcançar o desempenho reprodutivo esperado (Spitzer et al., 1995). Portanto, a manipulação da condição corporal durante a gestação pode ser o ponto de equilíbrio entre maior facilidade ao parto das novilhas em PCIG e o adequado desenvolvimento ao parto das vacas em PCFG.

As novilhas em PCFG chegaram ao início do período reprodutivo com $35 \mathrm{~kg}$ e 0,6 ponto de condição corporal a mais em relação àquelas em PCIG (Tabela 5). O peso vivo inicial de $346 \mathrm{~kg}$ das novilhas em PCFG representou 73,6\% do peso à maturidade de $470 \mathrm{~kg}$ das vacas multíparas do rebanho, enquanto o daquelas em PCIG correspondeu a $66,1 \%$ desse peso.

O maior peso relativo associado à maior condição corporal foi determinante para a taxa de prenhez e para o período da concepção no segundo período reprodutivo. A taxa de prenhez nas vacas em PCFG foi de $85 \%$, superior à de $53 \%$ verificadas naquelas em PCIG. O percentual de vacas prenhes no terço final do período reprodutivo foi de $33 \%$ nas vacas em PCIG, significativamente mais tardias que os $6 \%$ das vacas em PCFG.

Vacas primíparas aos 22/24 meses com baixa condição corporal ao parto não possuem tempo hábil de recuperação para concepção ao início do período reprodutivo, mesmo com desmame precoce de seus bezerros. Pilau \& Lobato 
Tabela 5 - Peso vivo e condição corporal ao início do segundo período reprodutivo, taxa de prenhez e ordem de concepção de vacas primíparas durante a gestação

\begin{tabular}{lcccrr}
\hline Sistema de alimentação & $\begin{array}{c}\text { Peso vivo } \\
\text { inicial, kg }\end{array}$ & $\begin{array}{c}\text { Condição corporal } \\
\text { inicial, 1-5 }\end{array}$ & Taxa de prenhez, \% & $\begin{array}{c}\text { Período de } \\
\text { concepção }(\%)\end{array}$ & $\begin{array}{c}\text { Inicial } \\
\text { Intermediário }\end{array}$ \\
\hline PCIG & $311 \mathrm{~b}$ & $2,9 \mathrm{~b}$ & 33 & 34 \\
PCFG & $346 \mathrm{a}$ & $3,5 \mathrm{a}$ & $85 \mathrm{~A}$ & 47 & 47 \\
Média & & & & 40 & 41 \\
\hline
\end{tabular}

a, b na mesma coluna, diferem $(\mathrm{P}<0,05)$ entre si.

Período: 27/10/2005-13/2/20/2006.

PCIG - pastagem de milheto na fase inicial de gestação e pastagem natural no pré-parto.

PCFG - pastagem natural na fase inicial de gestação e pastagem de aveia e azevém no pré-parto.

(2006) observaram taxa de prenhez de $77 \%$ e que $48 \%$ das primíparas ficaram prenhes no terço final do período reprodutivo. O elevado percentual de vacas em PCIG prenhes no terço final pode influenciar negativamente a taxa de prenhez no período reprodutivo subseqüente.

Em experimento com primíparas aos 34/36 meses de idade, Pio de Almeida et al. (2002) obtiveram baixas taxas de prenhez, como conseqüência da baixa condição corporal das vacas, que foi de $40 \%$ nas vacas com desmame dos bezerros aos 90 dias e de $11 \%$ nas vacas com desmame de seus bezerros aos 7/8 meses. Em primíparas, também com 34/36 meses de idade e moderada a alta condição corporal, Lobato et al. (2000) verificaram taxas de prenhez de 100\% com desmame dos bezerros aos 70 dias e de $89 \%$ em vacas com desmame de seus bezerros aos 7/8 meses. A taxa de prenhez de $85 \%$ daquelas em PCFG com cria ao pé pode, então, ser considerada altamente satisfatória para o sistema "um ano" de produção.

Não houve diferença em peso vivo das vacas ao final do período reprodutivo, média de $317 \mathrm{~kg}$ (Tabela 6). Entretanto, as vacas em PCFG tinham ao pé bezerros de $90 \mathrm{~kg}$, na média $9 \mathrm{~kg}$ mais pesados em relação aos daquelas em PCIG. Em trabalho realizado por Ciccioli et al. (2003), as vacas submetidas a alto nível nutricional desmamaram bezerros $10 \mathrm{~kg}$ mais pesados em relação àquelas expostas a níveis nutricionais moderados no pré e no pós-parto. Lobato et al.
(1998) observaram, em vacas submetidas a pastagens melhoradas no pré e pós-parto, seus bezerros $7 \mathrm{~kg}$ mais pesados em relação àquelas que não receberam suplemento. Estes autores também verificaram ganhos de peso mais acentuados durante o período reprodutivo nas vacas de baixo desempenho durante o pré e pós-parto.

A eficiência produtiva ao parto não foi alterada pelo sistema alimentar durante a gestação. A média foi de 28,6 kg de bezerro com 100 dias de idade $/ 100 \mathrm{~kg}$ de vaca. A eficiência produtiva ao final do período reprodutivo das vacas em PCFG foi superior à daquelas em PCIG, 28,1 vs $26,1 \mathrm{~kg}$ de bezerro com 100 dias de idade/100 kg de vaca.

As respostas obtidas comprovaram bom potencial produtivo para primíparas aos 22/24 meses de idade. O maior desempenho no período pré-parto proporcionou melhor eficiência produtiva para as vacas em PCFG, que apresentaram melhor desenvolvimento para cria de seus bezerros. A diminuição do número de categorias em desenvolvimento e a ausência de vacas não-gestantes proporcionadas pela redução da idade ao primeiro serviço e altas taxas de prenhez aumentaram a eficiência de estoque (Rovira, 1996; Pötter et al., 1998).

As vacas prenhes com bezerro ao pé apresentaram maior condição corporal ao parto e ao início do segundo período reprodutivo, além de maior intervalo do parto ao acasalamento. As vacas que emprenharam novamente

Tabela 6 - Peso da vaca ao final do período reprodutivo, peso do bezerro ajustado para 100 dias de idade e eficiência produtiva ao parto e ao final do período reprodutivo

\begin{tabular}{lcc}
\hline & \multicolumn{2}{c}{ Sistema de alimentação } \\
\cline { 2 - 3 } & PCIG & PCFG \\
\hline Peso vivo final da vaca & 313 & 320 \\
Peso do bezerro ajustado para 100 dias de idade & $81 \mathrm{~B}$ & 317 \\
Eficiência produtiva ao parto 1 & 29,1 & 28,0 \\
Eficiência produtiva ao final do período reprodutivo 1 & $26,1 \mathrm{~B}$ & $28,1 \mathrm{~A}$ \\
\hline
\end{tabular}

${ }_{1} \mathrm{~kg}$ de bezerro com 100 dias de idade/100 kg de vaca parida.

PCIG - pastagem de milheto na fase inicial de gestação e pastagem natural no pré-parto.

PCFG - pastagem natural na fase inicial de gestação e pastagem de aveia e azevém no pré-parto.

A, B na mesma linha, diferem $(\mathrm{P}<0,05)$ entre si.

$\mathrm{CV}=$ Coeficiente de variação. 
também tinham ao pé bezerros de mesma idade, mais pesados em relação às não-gestantes, ao final do segundo período reprodutivo (Tabela 7 ).

A maioria dos estudos com vacas de cria tem indicado que a nutrição pré-parto, avaliada pela condição corporal ao parto, é o principal determinante do retorno da atividade cíclica ovariana e do desempenho reprodutivo. Primíparas paridas com baixa condição corporal, mantendo ou perdendo mais condição durante a lactação, têm prolongado intervalo do parto ao primeiro estro, portanto, baixa fertilidade desmamando também bezerros mais leves (Ciccioli et al., 2003). De acordo com Rice (1991), em virtude da grande demanda por nutrientes para a lactação, os efeitos inibitórios da mamada pelo bezerro sobre a secreção de GnRH e de gonadotrofinas são mais acentuados em vacas com baixa condição corporal.

Além dos efeitos nutricionais, vacas não-prenhes são geneticamente mais tardias e devem ser eliminadas no processo de seleção do rebanho de cria. Elevadas taxas de prenhez possibilitam aumentar a taxa de reposição das matrizes, maior giro de capital e maior progresso genético. O sucesso de um programa de seleção depende da capacidade de diferenciar efeitos genéticos dos ambientais e a interação genótipo $\times$ ambiente visando obter indivíduos mais produtivos nas diversas situações de ambiente (Fries, 2004).

Tabela 7 - Desempenho de vacas primíparas prenhes e nãogestantes aos 25/28 meses de idade durante a gestação, ao parto, no pós-parto e no período reprodutivo e desenvolvimento dos bezerros do nascimento ao final do período reprodutivo

\begin{tabular}{lcc}
\hline & Prenhe & Não-gestante \\
\hline Peso vivo inicial (kg) & $283 \pm 31$ & $298 \pm 26$ \\
Condição corporal inicial (1-5) & $3,4 \pm 0,3$ & $3,3 \pm 0,2$ \\
Ganho médio diário (kg) & $0,284 \pm 0,1$ & $0,118 \pm 0,1$ \\
Ganho de condição corporal (1-5) & $-0,41 \pm 0,2$ & $-0,65 \pm 0,2$ \\
Pós-parto & & \\
Peso vivo (kg) & $297 \pm 36$ & $293 \pm 33$ \\
Condição corporal (1-5) & $3,1 \pm 0,3$ & $2,7 \pm 0,3 *$ \\
Ganho médio diário (kg) & $0,845 \pm 0,3$ & $0,552 \pm 0,8$ \\
Ganho de condição corporal (1-5) & $0,20 \pm 0,2$ & $0,25 \pm 0,4$ \\
Intervalo parto-acasalamento (dias) & $48 \pm 18$ & $31 \pm 12 *$ \\
Período reprodutivo & & \\
Peso vivo inicial (kg) & $335 \pm 35$ & $313 \pm 30$ \\
Condição corporal inicial (1-5) & $3,3 \pm 0,2$ & $2,9 \pm 0,3 *$ \\
Ganho médio diário (kg) & $-0,105 \pm 0,1$ & $0,049 \pm 0,2$ \\
Ganho de condição corporal (1-5) & $-0,25 \pm 0,2$ & $-0,16 \pm 0,3$ \\
Bezerro & & \\
Peso vivo ao nascer & & $27 \pm \pm 4$ \\
Peso vivo final & & \\
\hline
\end{tabular}

$* \mathrm{P}<0,05$

\section{Conclusões}

Maior nível nutricional pré-parto possibilita a novilhas prímíparas aos 22/24 meses de idade melhor desenvolvimento ao parto e ao início do período reprodutivo, de modo que aproximadamente $94 \%$ das concepções ocorrem nos períodos inicial e intermediário do acasalamento. Vacas primíparas aos 22/24 meses de idade submetidas a restrição alimentar pré-parto, mesmo com ganhos de peso próximos a $0,700 \mathrm{~kg} /$ dia na fase inicial da gestação, tiveram taxa de prenhez de $53 \%$, sendo um terço no período final do acasalamento.

\section{Literatura Citada}

ASSOCIATION OF OFFICIAL ANALYTICAL CHEMISTS - AOAC Official methods of analysis. 14.ed. Washington, D.C.: 1984. $1141 \mathrm{p}$.

BELLOWS, R.A.; GENHO, P.C.; MOORE, S.A. et al. Factors affecting dystocia in Brahman-cross heifers in subtropical Southeastern United States. Journal of Animal Science, v.74, n.7, p.1451-1456, 1996 .

BELLOWS, R.A.; SHORT, R.E. Reproductive losses in beef industry In: FIELDS, M.J.; SAND, R.S. (Eds.) Factors affecting calf crop. Gainesville: CRC Press, 1994. p.109-133.

BERETTA, V.; LOBATO, J.F.P.; MIELITZ NETTO, C.G.A. Produtividade e eficiência biológica de sistemas de produção de gado de corte de ciclo completo no Rio Grande do Sul. Revista Brasileira de Zootecnia, v.31, n.2, p.991-1001, 2002 (supl.).

BERGER, P.J.; CUBAS, A.C.; KOEHLER, K.J. et al. Factors affecting dystocia and early calf mortality in Angus cows and heifers. Journal of Animal Science, v.70, n.6, p.1775-1786, 1992.

BUCKLEY, B.A.; BAKER, J.F.; DICKERSON, G.E. et al. Body composition and tissue distribution from birth to 14 months of beef heifers. Journal of Animal Science, v.68, n.12, p.31093123, 1990.

CARVALHO, P.C.F.; MARÇAL, G.K.; RIBEIRO FILHO, H.M.N. et al. Pastagens altas podem limitar o consumo dos animais. In: REUNIÃO ANUAL DA SOCIEDADE BRASILEIRA DE ZOOTECNIA, 38., 2001, Piracicaba. Anais... Piracicaba: Sociedade Brasileira de Zootecnia, 2001. (CD-ROM).

CICCIOLI, N.H.; WETTEMANN, R.P.; SPICER, L.J. et al. Influence of body condition at calving and postpartum nutrition on endocrine function and reproductive performance of primiparous beef cows. Journal of Animal Science, v. 81 , n.12, p.3107-3120, 2003

EMPRESA BRASILEIRA DE PESQUISA E AGROPECUÁRIA EMBRAPA. Centro Nacional de Pesquisa de Solos. Sistema brasileiro de classificação de solos. Brasília: EMBRAPA Cerrados; Rio de Janeiro: Centro Nacional de Pesquisa de Solos, 1999. 412p.

FRIES, L.A. Critérios de seleção para um sistema de produção de ciclo curto. In: SEMINÁRIO DE AVALIAÇÃO DE BOVINOS DE CORTE E FORMAÇÃO DO CORPO DE JURADOS DA RAÇA ANGUS, 1., 2004, Esteio. Anais... Porto Alegre: Associação Brasileira de Criadores de Angus, 2004. p.74-88.

GIBB, M.J.; TREACHER, T.T. The effect of herbage allowance on herbage intake and performance of lambs grazing perennial ryegrass and red clover swards. Journal of Agricultural Science, v.86, p.355-365, 1976.

GOTTSCHALL, C.S.; LOBATO, J.F.P. Comportamento reprodutivo de vacas de corte primíparas submetidas a três lotações em 
campo nativo. Revista Brasileira de Zootecnia, v.25, n.1, p.46-57, 1996.

GRIMARD, B.P.; HUMBLOT, A.A.; PONTER, J.P. et al. Influence of postpartum energy restriction on energy status, plasma $\mathrm{LH}$ and oestradiol secretion and follicular development in suckled beef cows. Journal of Reproduction Fertility, v.104, p.173$179,1995$.

HIGHT, G.K. The effects of the under nutrition in late pregnancy on beef cattle production. New Zealand Agricultural Research, v.9, n.3, p.479-490, 1966.

KLINGMANN, D.L.; MILES, S.R.; MOTT, G.O. The cage method for determining consumption and yield of pasture herbage. Journal of Society of Agronomy, v.35, p.739-746, 1943

LOBATO, J.F.P.; MÜLlER, A.; PEREIRA NETO, O.A. et al. Efeitos da idade a desmama dos bezerros sobre o desempenho reprodutivo de vacas de corte primíparas. Revista Brasileira de Zootecnia, v.29, n.6, p.2013-2018, 2000 (supl.1).

LOBATO, J.F.P.; DERESZ, F.; LEBOUTE, E.M. et al. Pastagens melhoradas e suplementação alimentar no desempenho reprodutivo de vacas de corte primíparas. Revista Brasileira de Zootecnia, v.27, n.1, p.47-53, 1998.

LOWMAN, B.G.; SCOTT, N.; SOMERVILle, S. Condition scoring beef cattle. Edinburgh: East of Scotland College of Agriculture, 1973. 8p.

MERCK SHARP DOME - MSD. Improved reproductive performance in heifers. New Jersey: Copyright, 1992. 53p.

MORENO, J.A. Clima do Rio Grande do Sul. Porto Alegre: Secretaria da Agricultura, 1961. 41p.

MOTT, G.O. Relationship of available forage and animal performance in tropical grazing systems. In: FORAGE GRASSLAND CONFERENCE, 1984, Houston. Proceedings... Lexington: American Forage and Grassland Council, 1984. p.373-377.

MOTT, G.O.; LUCAS, H.L. The design conduct and interpretation of grazing trials on cultivated and improved pastures. In: INTERNATIONAL GRASSLAND CONGRESS, 6., 1952, Pensylvania. Proceedings... Pensylvania: State College Press, 1952. p.1380-1395.

NATIONAL RESEARCH COUNCIL - NRC. Nutrient requeriments of beef cattle. 7.ed. Washington, D.C.: National Academy Press, 1996. 404p.

PEREIRA NETTO, O.; LOBATO, J.F.P.; SIMEONE, A. Sistema de pastejo rotativo ponta e rapador para novilhas de corte. 1. Desempenho corporal. Revista Brasileira de Zootecnia, v.28, n.1, p.137-142, 1999.
PILAU, A.; LOBATO, J.F.P. Manejo alimentar de vacas primíparas aos 24/26 meses de idade em sistemas a pasto. In: REUNIÃO ANUAL DA SOCIEDADE BRASILEIRA DE ZOOTECNIA, 43. 2006, João Pessoa. Anais... João Pessoa: Sociedade Brasileira de Zootecnia, 2006. (CD-ROM).

PIO DE ALMEIDA, L.S.; LOBATO, J.F.P. Efeito da idade de desmame e suplementação no desenvolvimento de novilhas de corte. Revista Brasileira de Zootecnia, v.33, n.6, p.20862094, 2004 (supl. 2).

PIO DE ALMEIDA, L.S.; LOBATO, J.F.P.; SCHENKEL, F.S. Data de desmame e desempenho reprodutivo de vacas de corte Revista Brasileira de Zootecnia, v.31, n.3, p.1223-1229, 2002.

PÖTTER, L.; LOBATO, J.F.P.; MIELITZ NETTO, C.G.A Produtividade de um modelo de produção para novilhas de corte primíparas aos dois anos, três e quatro anos de idade. Revista Brasileira de Zootecnia, v.27, n.3, p.613-619, 1998.

RIBEIRO, E.L.A.; RESTLE, J.; ROCHA, M.A. et al. Eficiência produtiva em vacas primíparas das raças Aberdeen Angus e Charolês. Revista Brasileira de Zootecnia, v.30, n.1, p.125-132, 2001.

RICE, L.E. The effects of nutrition on reproductive performance of beef cattle. Dairy Nutrition Management, v.7, n.1, p.1-26, 1991 .

ROCHA, M.G.; PILAU, A.; SANTOS, D.T. et al. Desenvolvimento de bezerras de corte submetidas a diferentes sistemas alimentares Revista Brasileira de Zootecnia, v.33, n.6, p.2123-2131, 2004 (supl.2).

ROCHA, M.G.; RESTlE, J.; PILAU, A. et al. Produção animal e retorno econômico da suplementação em pastagem de aveia preta e azevém. Ciência Rural, v.33, n.3, p.85-93, 2003.

ROVIRA, J. Manejo nutritivo de los rodeos de cria en pastoreio. Montevideo: Hemisferio Sur, 1996. 288p.

SPITZER, J.C.; MORRISON, D.G.; WETTEMANN, R.P. et al. Reproductive responses and calf birth and weaning weights as affected by body condition at parturition and postpartum weight gain in primiparous beef cows. Journal of Animal Science, v.73, n.5, p.1251-1257, 1995.

STATISTICAL ANALYSIS SYSTEM - SAS. SAS/STAT user's guide: statistics. 4.ed. Version 6, Cary: 1997. v.2, 943p.

VIEIRA, A.; LOBATO, J.F.P.; TORRES JR., R.A.A. et al. Fatores determinantes do desempenho reprodutivo de vacas Nelore na região dos cerrados do Brasil Central. Revista Brasileira de Zootecnia, v.34, n.6, p.2408-2416, 2005 (supl.).

WILM, H.G.; COSTELLO, D.F.; KLIPPLE, G.E. Estimating forage yield by the double-sampling methods. Journal of American Society of Agronomy, v.36, p.194-203, 1944. 